\title{
PROMOTING IN COMPANIES A SUCCESSFUL CULTURE OF HEALTH AND SAFETY
}

\author{
R. CHAÏB ${ }^{1}$, M. TALEB ${ }^{2}$, M. BENIDIR ${ }^{1} \&$ I. VERZEA ${ }^{3}$ \\ ${ }^{1}$ Laboratory of Transport Engineering and Environment, University of Constantine 1, Algeria. \\ ${ }^{2}$ Sheikh Larbi Tebessi University, Tebessa, Algeria. \\ ${ }^{3}$ Technical University Gh. Asachi Iasi, Romania.
}

\begin{abstract}
In Algeria, the human consequences of occupational accidents - on the profitability and the added value - are many, knowing that a company is the employee's home and the damage of each may affect them as an entire body. Moreover, understanding and applying concepts of risk management in the Anglo-Saxon spirit is a completely absent approach in our companies. Preventive measures are still insufficient, especially for the protection of workers who are often left to their own. This leads to an uneven maturity of companies, different strategies considered and dissimilar organizational choices. More than 50,000 accidents/year were recorded in the Algerian companies, between 750 and 800 of those accidents have caused deaths. The number of days lost that are automatically compensated is estimated to $14 \times 10^{5}$. These costs are exorbitant for the whole society and even more so for the companies themselves (the continuing rise of absenteeism, disruption of ongoing work and lost production, etc.). Conscious of the importance of the industrial safety control for the future of our industrial heritage, we covet raise employees and employers awareness on the importance of all issues induced by the technological risks within companies. Everything has to be done in order to avoid an accident, which breaks or handicap a human life. Instantly, everything has to be done to ensure how to provide occupational health and make the industrial action daily to ensure the safety of its personnel in different companies or even in each workplace. Thus, a permanent anticipation of work accidents and occupational diseases can therefore be reached and to develop a permanent and sustainable culture of prevention in companies. Therefore, continuous improvement and permanent safety of health and protection of the employee is imposed and becomes a common goal. So, we hope that prevention is on the agenda of each employer, each worker, all employers' associations, trade unions and professional organizations. Safety and health at work should be seen as a tool for productivity and economic asset. Only in that way, individually and collectively the risks can be controlled and the source of dangers can be eliminated for health, safety and physical integrity of workers, while relying on the general principles of prevention: The health in the company is the health of the company.

Henceforth, legislation is essential but not sufficient to cope with these changes or to stay abreast of new risks. Therefore, companies especially those at high risk such as oil and cement industries must be able to identify risks and to fight against the problems arising in terms of safety and health at work and respond effectively in dynamic management strategies. We covet through this paper, guide and educate those concerned (state, employers and employees) of the austerity of industrial hygiene and safety within our companies. Thus, arrive at implemented priority actions of relevant preventions, improving the quality of life at work and the same improving industrial performance or promote a culture of prevention in Algerian companies.
\end{abstract}

Keywords: Cement plant, improvement, industrial hygiene and safety management, risks and preventive measures.

\section{INTRODUCTION}

Today, the focus on risk management in the company has increased. This translates simultaneously by a strengthened regulatory framework and by increasing pressure of the markets for company's awareness of the need to control their risks. Henceforth, the risks are events that prevent the company from achieving its strategic objectives: «the management of risks or risk management should be logic of the company» [1]. 
In principle, compliance with legislation, standards and recommendations in effect, health and safety of work should ensure conditions of adequacy. Unfortunately, today in practice, the situation is considerably more complex. On the one hand, technological progress and intense competitive pressures lead to rapid changes in conditions and in work processes and organization as well. On the other hand, the cost of accidents and occupational diseases is exorbitant for the whole society and, even more, for the company itself (the continuing rise of absenteeism, disruption of ongoing work and lost production, etc.) [2]. Henceforth, it is very difficult to guarantee a match between the actual risk involved and the preventive measures taken. Thus, legislation is necessary but not sufficient to cope with these changes and stay abreast of new risks. Therefore, organizations must be able to fight against the problems in terms of safety and health at work and to respond effectively in dynamic strategies of risk management [3]. The assessment of the potential risks in work place, and in any tasks, before the occurrence of malfunctions, accidents or occupational diseases, is a prerequisite in order to build an action plan for appropriate prevention [4]. So, the occupational risk assessment, initial stage of a health and safety policy at work, is to identify and classify risks in the company, to implement priority actions of relevant prevention being obvious. Henceforth, the employer has the obligation and the duty to organize the safety and health at work. Implementation of a system of safety management and occupational health it provides an effective means to fulfill them [5]. Henceforth, the company's role is to assess measures that will facilitate individual awareness and enable all employees to take charge of their own physical and mental health [6] «employees are the key to success».

\section{WHY THIS WORK?}

Health and safety play an important role in our daily life. We constantly perform choice and take decisions that affect our health and safety. The magnitude of impact on a global scale in terms of human suffering and economic costs of occupational accidents and occupational diseases, as well as major industrial disasters, has long been a concern in the work place as national and international. Now, work accidents and occupational diseases (WA/ODs)are malfunctions that cause great suffering and loss of lives. In Algeria, the health problems in the workplace are now an enormous burden, both health and economic, on workers, companies and society in general. The situation is distressing; the least we can say is that the situation is alarming, even catastrophic because of the state of neglect in which the government has left the field of prevention in the workplace. More than 50,000 accidents/year have been recorded; between 750 and 800 of those accidents have caused deaths, an average of three deaths a day. The economic cost is very high estimated at 19 billion dinars for the year 2012. These expenditures reveal serious shortcomings in health and safety at work for an industrialized country can afford in terms of prevention. Only 18 Algerian companies have integrated into their system in terms of prevention of occupational hazards and safety. As a result, a culture of recklessness developed at our companies. Consequently, for a first step, an orientation foe attention to general principles of prevention and good practice is essential in the company and becomes everyone's business, «believe in safety is risky» [7]. Fortunately, all these health and safety problems at work do not really attract the public attention, otherwise chaos or panic can be installed! They rarely gave the deserved importance. That must be changed and actions should be stimulated both at national and international levels and accelerating pace [8]. In addition, it can be noted that in companies' workers, in their majority, have not always been aware and concerned by the health and safety concepts. Now, our health and personal safety include a wide range of decisions and daily activities (e.g., information 
on the risks and occupational diseases, use of safety equipment at work, etc.). «It is recommended to make confident decisions. If not, you may have a hard life.» That is why whenever an accident or incident occurs, it is useful for the proper functioning of the company to seek all causes that are the source. Beyond the legal obligations, this work is a contribution to promote health and safety at work in our companies and uncover best practices and fundamental benefits of prevention in the workplace including:

$\checkmark$ Protect workers: protect life, preserve the integrity, and maintain health workers face the risk of accidents and diseases. Help in providing a rewarding work environment, without stress, favorable to a positive and nurturing of human resources «Human performance is best when people are physically and emotionally able to work and that they want to work [9]».

$\checkmark$ Protect functions: it is quite clear that workforce in a good health improves productivity and profits for companies and national economies by reducing the number of accidents and diseases, and therefore that requests for interventions and insurance compensation [10].

$\checkmark$ Improve company's profitability: investments in health and safety are synonymous related to the direct impact on the reducing insurance costs. Prevention also causes indirect benefits, including avoiding expenses related to the costs of absenteeism and recruitment. In addition, the benefits of increases profitability result in significant economies of scale at the macro level.

$\checkmark$ Increase productivity: investing in prevention contributes to making workers and thus the whole company more productive. The integration values health and safety in the tasks performance is often synonymous with time saving and increased mobilization of workers.

$\checkmark$ Contribute to a positive corporate image: a sound prevention program sends a positive corporate to all public of the company. In contrast, the media of an accident at work is severe and on a long run, can damage the image of the company.

\section{PLACE OF SAFETY AND HEALTH AT WORK}

First, it should be noted that the protection of workers against sickness, disease and injury arising out of work is a fundamental element of social justice. The right conditions and a decent workplace, safe and healthy, have been reaffirmed by the declaration of Philadelphia of 1944 and the International Labour Organization (ILO) declaration on social justice for a fair globalization [11]. Now, accidents and occupational diseases are malfunctions that cause great suffering and loss of life. Thus, the health of employees is a tremendous source of effectiveness in work and thus individual and collective performance. Work and health even maintain a double relationship: on the one hand, health is a prerequisite for the quality of work. On the other hand, the work carried out under proper conditions is a supporting factor in health and personal fulfillment. The health of employees is the first case of managers, it cannot outsource. In everyday life, the local manager who organizes the collective work and takes decisions closer to employees is the first guarantor. It is also an essential link with the corporate hierarchy: this is what makes up the difficulties faced by employees and informs them about the policies and projects of the company. Its role is essential listening: it is interesting to note that $64 \%$ of employees would like to be better heard, develop opportunities for informal exchange with their immediate supervisor. There has been progress on many fronts in the workplace. But deaths, accidents and diseases remain a serious concern. Safety at work must be an element of decent work. It aims to develop a list of measures to prevent the 
recurrence of the accident or incident. Measures may involve all areas: technical, organizational, informational, educational, etc. It is hoped through this work, raise the entities responsible for protecting the health of workers and to minimize the number of accidents and arrive at the sustainability of the industrial heritage. Therefore; it follows that the only way to deal with risks in general and relevant, it is a strategy of prevention. To be most effective, this prevention must begin developing working methods. It should also be remembered that «if accidents are costly, their prejudices are an investment».

\section{DIRECT AND INDIRECT IMPACTS}

WA/ODs are very expensive and can have many serious effects, direct and indirect effects on the lives of workers and their families, as well as of employers and environment. It is estimated that the cost of accidents and occupational diseases is also huge for employers. For a small company, the cost of a very serious or fatal accident of an employee may have significant negative economic consequences, even questioning the survival of the company.

\subsection{Direct costs}

For workers, the direct costs of an injury or illness include:

$\checkmark$ Pain due to injury or illness;

$\checkmark$ Loss of income;

$\checkmark$ Risk of losing job;

$\checkmark$ The cost of medical treatement.

For employers, direct costs include:

$\checkmark$ Absenteeism;

$\checkmark$ Payment for work not done;

$\checkmark$ Medical expences and allowances;

$\checkmark$ Repair or replacement of damaged machinery and equipment;

$\checkmark$ Reduction or temporary cessation of production;

$\checkmark$ Increased spending on training and adminstration;

$\checkmark$ Possible reduction in the quality of work;

$\checkmark$ Delivery delays;

$\checkmark$ Poor image;

$\checkmark$ Negative effect on the morale of other workers.

\subsection{Indirect Costs}

It was estimated that the indirect costs of an accident or illness can be four to ten times the amount of direct costs or even more. An illness or accident can cause so many indirect costs for workers, which usually are difficult to measure. One of the most obvious is the suffering caused to the worker's family, no compensation can compensate the loss. Indirect costs are:

$\checkmark$ The injured or ill worker should be replaced;

$\checkmark$ A new worker should be trained and must be given time to adapt;

$\checkmark$ It takes some time for the new worker to be as productive as the former one; 
$\checkmark$ Enough time must be given to the mandatory investigations to reporting and to various formalities;

$\checkmark$ The other workers are deeply concerned by accidents and have a negative influence on the relations between workers and employers;

$\checkmark$ The existence of unsanitary conditions and safety in the work place can also give a negative image of the company.

Therefore, this works gradually moving companies toward the implementation of a prevention policy, relying heavily on regulation and the 'inevitable' risk assessment. It should allow companies managers, employees and their representatives to:

- Better manage the professional risks;

- Respect the physical integrity of each, for a proper evaluation and implementation of preventive measures, taking into account the work organization and its technical and human components;

- Assist in compliance with the applicable legislation;

- Improve working conditions and employees welfare;

- Engage in a process of continuous improvement in health and safety at the workplace;

- And more broadly, to improve working conditions in a continuous and sustainable culture of prevention at each company.

One of expected outcomes of this study is to better focus prevention activities in Algerian companies.

\section{GENERAL PRINCIPLES OF PREVENTION}

The purpose of these principles is to reduce the risks in the entity considered, «the risk is formed by every event likely to lose money in company». Therefore everyone has a role to play in preserving the health and safety of people in a company. These principles can also be incorporated in the prevention of multifactorial (organizational, human, technical, etc.) of occupational hazards. Many contemporary studies confirm the positive effects of promoting programs of health and safety at work, based on the general principles of prevention, not only on employees (reduced absenteeism, reduced staff turnover, improved employee productivity, increase the attraction and detention staff), but also on employees and their families (well being, home atmosphere of happiness, less stress, less nervousness, calm, satisfied, cool, etc.). Certainly, several studies also claim gains in terms of finance, in particular concerning indemnisations compensation of employees and the cost of insurance. Therefore incorporate these principles into daily decisions can anticipate the consequences of choosing the company health workers and act accordingly.

However, the problem of occupational health that currently exists and tends to spread will not be curbed as long as the factors that are at its origin will not be determined, recognized and corrected $[12,13]$. Good organization can save time, avoid generating incidents of accidents, to reconcile the quality and safety [14]. The general prevention principles can be presented as follows [15]:

- Avoiding risks: Remove the hazard or exposure to it.

- Evaluating risks: Appreciate their nature and importance, especially during the development of the unique document of occupational risk assessment to determine the actions needed to ensure the safety and protect the health of workers. 
- Examples: Characterize all exposure circumstances, including during the upstream and downstream phases and foreseeable abnormal phases (a crowed floor, messy).

- Combating the risks at source: Integrate prevention as early as possible in the design of equipment, operating methods and workplaces. Examples: Capturing the emanations of a solvent;

- Adapting the work to man: Particularly concerning the design of work stations and the choice of work equipment and methods of work and production, particularly in order to limit the monotonous work and work-rate and to reduce the adverse effects of these on health.

- Examples: Integrating from the design the removal of hazards or to reduce exposures.

- Considering the state of technical development: Maintaining watch for implementing preventing measures in phase with technical and organizational developments. Examples: Establishing a technical/technological and organizational monitoring.

- Replacing what is dangerous by what is not or what is less dangerous: Avoid the use of processes or hazardous products when the same result can be obtained with a method with lower risks.

- Examples: Use a less hazardous product, it will be necessary to pay special attention to the new product (toxicity, physico-chimiques properties).

- Prevention planning: integrating it into a coherent whole, the technique, work organization, working conditions, social relationships and the influence of environmental factors.

- Examples: Schedule preventive measures within action plans.

- Taking collective protection measures by providing them priority over the individual protective measures. Only use personal protective equipment in addition to collective protection or an effective collective protection default. Examples: Information on the monitoring of the protection effectiveness.

- Giving appropriate instructions to workers: Giving employees the information necessary to perform their tasks in optimal safety conditions. This includes providing them with the necessary elements for the understanding of risks and thus to associate them in the process of prevention.

Example: Sensitize, inform, train and remind whenever necessary.

\section{SOME RECOMMENDATIONS TO REDUCE THE RISK \\ IN A COMPANY [14, 16-18]}

6.1 Risks associated with work equipments

- Use machines and tools in compliance with regulatory requirements;

- Integrate the safety aspect when buying;

- Use work equipment as prescribed by the supplier;

- Facilitate the operations of assembly and disassembly tools;

- Install a protective cover to sharp tools parts (envelop, equipped site) when they are no longer in use;

- Record the work equipment before any repair or maintenance;

- Establish procedures incorporating safety;

- Train staff;

- Ensure the wearing of required personal protective equipment (goggles, gloves, etc.). 


\subsection{Chemical risks}

- Replace a hazardous material with a less hazardous one;

- Limit the products handling;

- Check the labeling of supplied materials and properly label the split units:

- Supply products in the most convenient packaging for use;

- Capture products delivered by the source (cab, hood, etc.) and ventilate the area;

- Inform staff of precautions for use of products;

- Eliminate leakage products;

- To wear appropriate personal protective equipment de protection individually adapts (gloves, goggles, respirators, etc.);

- Establish safe operating procedures;

- Consider the processing, storage and waste disposal.

\subsection{Risks associated with electrical installations}

- Recording facilities before any intervention;

- To carry out electrical installations by qualified personnel with appropriate equipment:

- Periodically check the electrical installations;

- Inform staff of electrical hazards: marking of danger areas, access restrictions, emergency instructions;

- Train staff and to issue securities in accordance with the enabling tasks to be performed;

- Ensure the closure of cabinets, cupboard and electrical rooms.

\subsection{Physical risks}

- Remove the noise sources, limit its intensity;

- Put the facilities and noise equipment in separate and isolated areas;

- Install protections: rollover, cabinet, cab, acoustic treatment of the local walls;

- Limit the noise exposure time to staff;

- To wear personal protective equipment: ear plugs, ear muffs, etc.;

- Ensure that lighting is adequate and appropriate for the type of work to be done;

- Focus on natural light wherever possible;

- Set up work for light and suitable positions;

- Adapting workplaces to the characteristics and people abilities;

- Eliminate vibrations emitted by certain plant or machinery;

- Avoid workplaces at low or high temperature;

- Ensure adequate natural or forced ventilation in areas or confined workplaces;

- Protect the devices emitting ionizing radiation.

\subsection{Manual activities}

- Organize work stations to eliminate or reduce the handling;

- Limit the unit weight of handled loads;

- Use of handling equipment: pallet, trolley, etc.;

- Use proper upgrade means: lift table dock, lift gate, etc.; 
- Equip loads of handles means: handles, suckers, trays, etc.;

- Train staff to adopt appropriate gestures and postures;

- Limit the tasks duration that require repetition;

- To wear personal protective equipment: gloves, shoes, etc.

\subsection{Mechanical handling, moving}

- Ways and means for handling and accessories comply with regulations;

- Only use suitable means to the task to be done, under the conditions and the requirements of the manufacturer;

- Regularly check their condition and regulatory checks;

- Limit their use to only trained and certified and found able;

- To ensure visibility and in good soil;

- Organize the flow of people and vehicles;

- Report and maintain roads and maneuvering areas.

\subsection{Fire risk - explosions}

- Organize storage taking into account the products compatibility;

- Replace hazardous products with a less hazardous;

- Remove the sources proximity: flame, cigarette, welding equipment, etc.;

- Install protections: isolated rooms, wall and fire door;

- Install appropriate extinguishing means: fire extinguishers, fire blankets, etc.;

- Installing detection means and alarm;

- Establish intervention plans (fire instructions, exercise with fire brigade, etc.) and evacuation (emergency exit, signs, etc.).

\subsection{Workplaces}

\subsubsection{Movements on the ground floor}

- Organize the persons movements within the establishment precincts;

- Remove hazardous areas by placing flooring: non-slipping, removing ground inequalities (small step, stage, nick, etc.) and enlargement of the passages;

- Maintain soil: periodic cleaning and immediate in case of product application, repair of detective parts, etc.;

- Maintain wide passages, released, reported and enlighten. Outlaw storage.

\subsubsection{Risks of falls from height}

- Remove areas with level difference and height access;

- Establish protections: hand rails, guard rail, fence lock, cargo net, etc.;

- Use the moving platforms to the height work time;

- Train staff to ensure the correct use of mobile devices and a regular check of their strength;

- To carry personal protection (harnesses, stop falling, etc.);

- Avoid the use of ladders as workstations. 


\subsection{Road traffic}

- Anticipate the travel arrangements: schedule, duration, recommended route, specific plan for access to the destination;

- Maintain vehicles regularly;

- Repair immediately in case of failure;

- Organize working time;

- Train staff on how to drive safely.

\section{INDIVIDUAL BEHAVIOR}

Greater vigilance against the dangers can help reduce your risk of injury. Thus, beyond the technical and organizational measures, a responsible company may also seek to promote among its employees a healthier lifestyle, to empower health, with particular emphasis on prevention of serious and frequent illnesses (cardiovascular, cancer, diabetes) and the benefits of a healthy lifestyle [6]. The employees' individual hygiene staff participates in the occupational health [17, 19] «It is my responsibility to ensure my own safety» [20].Working conditions have also a relevant impact on health. Conversely, individual behavior in terms of wearing personal protective equipment, hand washing, respiratory hygiene, hydration, nutrition, sleep or physical activity affect health and safety at work and must be adapted to the professional activity. Personal hygiene is part of preventive measures against occupational diseases [21].

The hands are a major vector of contamination, for himself or his/her environment (both private and professional), sometimes through useful objects (door handles, tools, pencils, telephone, etc.). The work clothes can also be contaminated: they represent a serious risk for the employee and his entourage.

The occupational health necessarily requires regular cleaning of the hands, clothing used during labor and personal protective equipment.

Henceforth, bacteria, viruses, chemical and biological stains, dust, etc., can carry a large number of chemical or biological substances potentially hazardous to health by their hands and work clothes. Some hygiene at work aided and supported by an appropriate organization, can prevent some of the risks associated with these professional nuisances.

The occupational health is based mainly on [19]:

- Individual behavior (wearing appropriate protective equipment, hand washing, nutrition, hydration and sleep adapted to the work constraints, physical activity);

- Suitable workplace (installations sanitation, ventilation and clean air, rest room and catering, etc.);

- Maintenance and regular cleaning of the premises and work equipment.

Issues relating to personal hygiene are difficult to address because the personal employees sphere. Companies can, through occupational doctors and responsible of health and safety, give their employees some advice (awareness, display, information, etc.).

Therefore, the employer must implement measures to reduce occupational hazards, to inform employees to focus on behavior and to available appropriate equipment. Sanitation facilities have sinks, toilets, changing rooms and if necessary, showers in sufficient numbers and in good state. 
Organizational measures must be based on sound analysis of working conditions: to have points close to washing dirty jobs, ensure regular cleaning of these facilities, ensuring the comforts and privacy of users, etc. «Resolving problems that I can stay another day on this earth.» [20]

Another innovative element that must be adopted for a new community strategic vision that is well being at work. The latter takes into account the changes in the world at work and the emergence of new risks, in particular psychosocial, violence, stress, Musculoskeletal disorders (MSDs), moral or sexual harassment at work, etc.; and also to improve the quality of work that a healthy and safe work environment [22]. Well being is an essential component of Health and Safety at work.

It is quite clear that healthy workforce improves the productivity of companies and national economies by reducing the number of accidents and diseases, and therefore, that of requests for interventions and insurance compensation [10]. In addition, to established measures to prevent and control hazards and risks, it is necessary to develop and implement new strategies and solutions, both for the well-known hazards and risks, such as those related to certain substances, machinery, tools and manual handling, and for the new problems, such as biological risks, the psychosocial risks and musculoskeletal.

Finally, it should be noted that the repeated lack of sleep can have adverse consequences (hypertension, gastrointestinal disorders, viral infections, depression, headache, loss of motivation, learning disabilities, school dropouts and professional concerns), drowsy driving and the leading cause of motorways accidents. Sleep deserves its rightful place and it is important to sleep well and enough to meet the challenges of each new day [23]. Thus, the quality and duration of sleep or rest have a significant impact on work. Disturbed sleep can cause drowsiness', loss of alertness and an increased accidents risk.

\section{ROLES OF EMPLOYERS}

Today, prevention is not only intended just to reduce the number of accidents and occupational diseases, but also to eliminate or, at least, to reduce the overall professional risks [24]. It has been convinced that the trend toward 'zero risk' is not only possible but is also a necessity that requires a permanent and sustainable prevention of risks. Therefore, employers are urged to take seriously the issues of health and safety at work and do not force workers to adapt to hazardous conditions.

Therefore, the role of company is not only to write instructions and put posters on the walls, but also to implement measures that will facilitate industrial awareness for the employee's welfare and admitting everyone to take responsibility for their own physical and mental health. Studies indicate that the uncertainty and the lack of accurate knowledge about the danger increases perceived risk. Furthermore, the attitude toward the risk is highly variable from one individual to another [25]. Henceforth, the protection of health and safety at work is the stepping stone around which labor law is gradually built. Therefore, the prevention of occupational hazards and improving working conditions is involved in the valuation of trades and maintaining quality jobs. All active and voluntary approach facilitates access to employment, increases well being and, also, improves company's performance. It becomes necessary to require employers to provide comfort and hygiene for workers, to develop the individual and collective protection, to undertake general hygiene in the premises and especially about the risks potential particularly for high risk work such as cement, petroleum and construction works. The presence of field representatives Health, safety and environment (HSE) is a real act of communication [26]. It should be known that the perception of risk by individuals is also subject to large variations. 
The acceptable risk varies in effect if it is a risk «passive» (suffered by the individual, such as dietary risk taken into catering) or «active» (chosen by the individual), e.g., tobacco consumption): overall risks «active» are more readily accepted than risks «passive» [25].

For all these reasons, the industry must act daily to ensure the safety of its personnel in different companies or even in each workstation and continuously anticipate accidents. They also ensure that occupational health is assured sustainably: The corporate health is the health of the company! It should also be noted that the involvement and increasing awareness of workers in issues of health and safety at work have contributed to the consideration of the prevention and precaution as important tools in risk management.

Henceforth, the best way to save is to avoid accidents. How? By supporting health and safety in the company together with workers. And if there are accidents? The best way to minimize costs is to ensure that workers can quickly return in a sustainable way to work. Thus, risk analysis is a way to organize the information available on a given potential event, bring in probabilities based on assumptions, variability and uncertainty and deduce logically from decisions. This approach may be applied to a variety of fields [25]. Moreover, each of us unconsciously uses it several times a day, in a qualitative way, to make decisions in daily life. For that, the company should identify and assess all potential risks associated with the occupational activity [27].

In many countries, this obligation is enshrined in the regulatory health and safety at work. However, small and medium companies, in particular, still struggling to identify risks and implement preventive measures required. Finally, it must always be remembered the «the tiles that protect from rain were all put in good weather».

\section{CONCLUSIONS}

The culture of risk culture for a company is reflected in the level of risk taking into account by the setting up strategy of the company and its organization. Accordingly, any company is concerned by that, whatever its size and its activity sector. To do so, the employer must meet its obligations for health and safety at work and make the field presence to remember safety rules. Hence, the importance of a shared common safety culture to all actors and all risks must be emphasized. «Safety is a priority of any industrial activity». Specialized institutes, research laboratories and universities must accept or, better, voluntarily adopt a positive approach of coordination to achieve a communion of their efforts more effective and more clear for the company. The development of specialized courses in industrial hygiene and safety should be pursued with perseverance. The development of initial and continuing training should focus on joint training of all stakeholders to encourage their cooperation throughout the proceedings of the risk management (role of research laboratories).

From now on, safety and prevention of accidents are an absolute necessity for the survival of the organizational entity. It is a priority of company or, even to any industrial activity. Immediately, the experience has shown that prevention reduces the risk, accidents can be avoided [28] and that success is related to the actions' coherence. Priorities must be stated to guide the best choice of company. Thus, in order to change radically the company in this matter, «prevention is everybody's business» must be integrated and put into practice, involving the all staff in the management approach of prevention «There are signs and procedures to read. If something is not right, I have to warn up». For the improvement of the health and safety of employees, every company must engage itself in a continuous improvement process. Thus, those responsible for health and safety at workplace have to relate within organizations, and the companies must operate in a working environment constantly changing 
on technological, economic, legislative, social and cultural levels [29]. The following best practices of prevention are recommended [30]:

1. Integrate the health and safety management in all company functions;

2. Harmonize health and safety policy with other company policies;

3. Developing the company autonomy in terms of prevention;

4. Encourage a multidisciplinary approach;

5. Make the identification and evaluation of a priori risk of a major health policy and safety;

6. Integrate prevention into the design of premises, equipment, jobs and working methods;

7. Analyzing accidents and occupational diseases caused earlier;

8. Improve risk management policy and develop the company base values. «I am telling my boss that I do not know so he could train me before I go.»

Finally, the emphasize is given to the importance of a tripartite commitment and action at national level to promote a preventive approach and a culture of safety, essential if sustainable improvements in safety and health at work are to be achieved. Thus, any decent work must be a safe work: «Corporate culture is the set of values, principles and representations is shared by all of the entity».

\section{REFERENCES}

[1] Jérémie LACROIX, Analyse et gestion des risques dans les grandes entreprises: impacts et rôle pour la dsi, Cigref, 2007.

[2] Anthony Colombani-Poggi, Les pratiques de gestion prévisionnelle dans les centres de gestion: Éléments pour un premier bilan, CIG grande couronne, service Analyse et prospective sociale, 2005.

[3] Chaib Rachid \& Ion Verzea, Strategy of a continuous improvement steps in safety: case of shovel and cranes factory, Management of technological changes "MTC 2009", September 3TH-5TH Alexandroupolis, Greece.

[4] Ghania Chaib, Rachid Chaib \& Ion Verzea, From the risks evaluation to the health and safety preservation at work. Environment Engineering and Management Journal, 8(3), pp. 483-486, May/June 2009.

[5] BIT, Principes directeurs concernant les systèmes de gestion de la sécurité et de la santé au travail, ILO-OSH, ISBN 92-2-211634-8, Bureau International du travail Genève 2002.

[6] G. Künzi, J.-C. Rielle, Manager la santé dans l'entreprise, PME et développement durable, Editions Carrefour Prévention, Genève, 1998.

[7] Isabelle Corréard, Patrick Anaya \& Patrick Brun, Sécurité, hygiène et risques professionnels, Dunod, Paris, 2011. ISBN 978-2-10-056166-7.

[8] BIT, Stratégie globale en matière de sécurité et de santé au travail, conclusions adoptées par la conférence internationale du travail à sa 91e session, 2003. ISBN 92-2-216287-0.

[9] Agence se sante et des services sociaux de Montréal, Guide pour la promotion de milieu de travail sains dans le réseau de la sante et des services sociaux. ISBN 978-2-89510780-4, Pour des milieux de vie en santé, Québec, 2011.

[10] Dr Sameera Al-Tuwaijri, Directrice du Département Safework du BIT; Une journée pour la santé et la sécurité au travail, le 29/04/08.

[11] Déclaration de l'OIT sur la justice sociale pour une mondialisation équitable, Conférence internationale du Travail, 97e session, Genève, 10 juin 2008. 
[12] Estelle Morin, Sens du travail, santé mentale et engagement organisationnel; santé psychologique; Etudes et recherches, Rapport R-543, ISSN: 0820-8395, 2008.

[13] Centre Patronal de santé et sécurité du travail au Québec; Les outils du comité de santésécurité: guide pratique, ISBN 2-922991-35-0. Mise à jour aout 2005, Québec, Canada.

[14] M. Bossard et al, Les activités de mise en propreté et services associés, prévention des risques, ED 963, INRS 2005.

[15] Dossier travail et sécurité, Protection Individuelle, INRS, mise à jour 09/01/2006.

[16] Service de santé au travail, L'évaluation des risques professionnels: le document unique, ASMI, Annecy, novembre 2002.

[17] C. Soudry, Mise à disposition et port des équipements de protection individuelle; Droit en pratique, Travail et sécurité, $\mathrm{N}^{\circ} 636$, janvier 2004.

[18] R. Chaib, I. Verzea, M. Benidir \& M. Taleb, Promoting a culture of health and safety at work: safety a permanent priority, WIT Transactions on Information and Communication Technologies Series Volume: 44, ed. C.A. Brebbia, Wessex Institute of Technology: Southampton, UK, 2012. ISBN: 978-1-84564-620-2.

[19] Dossier; Hygiène au travail: pour aller plus loin, INRS, ED583, mise à jour 02/07/2009.

[20] Silvy Moleman, La santé et la sécurité $\sim$ Des choix pour la vie Cahier d'activités élaboré par Travail sécuritaire NB pour les écoles néo-brunswickoises, de la maternelle à la 12e année, Mise en œuvre: Janvier 2001.

[21] Dossier travail et sécurité $\mathrm{N}^{\circ} 616$, Hygiène corporelle sur les lieux de travail: l'eau, source de propreté, INRS, mars 2002.

[22] Vincent Grosjean, Hygiène et sécurité du travail, cahier de notes documentaires, $1^{\text {er }}$ trimestre 2005, INRS, ND 2223-198-05.

[23] Damien Léger, Alain Nicolas, Joël Paquereau, Sylvie Royant-Parola et Véronique ViotBlanc; Bien dormir, mieux vivre, le sommeil c'est la santé, Réf: 421-09648-B, 2009.

[24] Barbara Dufour \& R. Pouillot, Approche qualitative du risque. Epidémiologie et Santé Animale, 2002, 41, pp. 35-43.

[25] B. Toma, Barbara Dufour \& M. Sanaa, Généralités sur l'analyse de risque. Epidémiologie et Santé Animale, 2002, 41, pp. 5-17.

[26] Benoît Péribère, Le guide de la sécurité au travail! Les outils du responsable; Afnor éditions 2010, ISBN 978-2-12-465245-7.

[27] S. Auduberteau \& K. Ganino, La prévention des risques professionnels: hygiène et sécurité au travail, collection «les diagnostics de l'emploi territorial» hors série $\mathrm{N}^{\circ} 5$, Direction Recrutement et Protection Sociale, octobre 2003.

[28] Bertrand. Collomb, Président directeur Général, Politique santé et sécurité Groupe, Ensemble, faire de Lafarge l'entreprise la plus sure de son secteur, Lafarge, Septembre 2002.

[29] Jean-Pierre Brun \& Claude D. Loiselle, Le métier de préventionniste: contexte de travail et profils d'activités. Relations industrielles/Industrial Relations, 56(1), 2001, pp. 141-164. ISSN 0034-379X.

[30] Politique de maîtrise des risques professionnels, Valeurs essentielles et bonnes pratiques de prévention ; Valeurs Essentielles: Institution Prévention (CNAMTS, INRS, CRAM, CGSS, EUROGIP) CNICC du 29 mai 2001. 